\title{
Parallel effects of aging and time pressure on memory for source: Evidence from the spacing effect
}

\author{
AARON S. BENJAMIN and FERGUS I. M. CRAIK \\ University of Toronto and the Rotman Research Institute, Toronto, Ontario, Canada
}

\begin{abstract}
Two experiments address the degree to which item memory - the ability to remember that a word has been presented-is dissociable from source memory, or the ability to remember the context of that word's presentation. Spacing (as opposed to massing) an item's two presentations leads young adults to endorse that item more often when they are instructed to recognize it and to reject it more often when they are instructed to exclude it. Old adults also enjoy beneficial effects of spacing when the item is to be recognized, but suffer detrimental effects of the spacing manipulation when the item is to be rejected:They falsely endorse the spaced to-be-rejecteditems more than the massed ones. This dissociation also obtains with young subjects under conditions of increased time pressure: Under normal decision conditions, the ability to endorse to-be-recognizeditems and to reject to-be-rejecteditems increases with spacing; under speeded conditions, the ability to reject the latter items decreases with spacing. The results support the notion that source memory is selectively impaired in the elderly and that it is difficult to access mnemonic information about source under time pressure.
\end{abstract}

The ability to accurately remember the origin of knowledge that we possess affords us the capacity to know what facts are relevant to a given situation and further keeps us from making embarrassing or costly mistakes, such as repeating a joke to a friend or mistakenly identifying a casual acquaintance as a criminal in a police lineup. Such lapses of memory are notable for the failure to coordinate familiarity with its source. In this article, we examine the dissociability of these two memorial bases: knowledge that an event has occurred (item memory) and knowledge of the context in which it occurred (source memory). In the first experiment, we investigated the differential effects of time pressure on retrieval of item and source information in memorial decisions. In the second experiment, the effects of aging on the retrieval of item and source memory were examined. Researchers have noted that these and other resource-compromising variables exhibit similar effects (e.g., Craik \& Jacoby, 1996) and may be related to a reduction in the efficacy of consciously controlled processes (e.g., Jacoby, 1999) and impaired frontal function (Kimberg \& Farah, 1993).

From a practical perspective, we can all distinguish between cases in which we have a memory that something has occurred versus when, how, or where it has occurred. We may remember that we put our glasses down, but not where, or that we were supposed to meet someone, but not

We thank Sharyn Kreuger for her assistance with the experiments. Correspondence regarding this article should be addressed to A. S. Benjamin, Department of Psychology, 603 E. Daniel St., University of Illinois, Champaign, IL 61820 (e-mail: asbenjam@s.psych.uiuc.edu). whom. Such a commonsense distinction maps roughly onto prevalent dichotomies evident in the language of $\operatorname{cog}$ nitive memory research: semantic versus episodic memories (Tulving, 1983), familiarity versus retrieval (Mandler, 1980), and familiarity versus recollection (Jacoby, 1991). The ubiquity of such a distinction reflects how critical dissociations of the sort we describe here are in current theorizing about human memory. Moreover, it appears that source information is a component of memory that is selectively impaired in the elderly (e.g., Spencer $\& \mathrm{Raz}, 1995)$. It is of both practical and theoretical importance to understand the nature of such deficits, as well as what other variables might elicit similar effects in young adult subjects.

Older adults demonstrate difficulty with tasks such as reality monitoring (Hashtroudi, Johnson, \& Chrosniak, 1989) and recall of the gender of the presenter of studied stimulus items (Kausler \& Puckett, 1981) that demand the retrieval of contextual aspects of the encoding situation. One example of older adults' inability to remember the source of learned information is provided by McIntyre and Craik (1987). In their experiment, both young and old subjects were taught invented "facts" about celebrities. After a week, when asked to recall those facts and to state where they had learned them, older subjects were much less likely to accurately attribute the source of a remembered experimental fact to the earlier study episode. Other studies have also shown age-related deficits in source memory (e.g., Schacter, Osowiecki, Kaszniak, Kihlstrom, \& Valdesseri, 1994); reviews of such findings are provided by Craik and Jennings (1992), Spencer and Raz (1995), and Verhaeghen, Marcoen, and Goossens (1993). 
In addition, neuropsychological evidence for the dissociable contributions of these two different forms of memory is available (Benjamin, Kester, Craik, \& Black, in press; Curran, Schacter, Norman, \& Galluccio, 1997; Parkin, Bindschaedler, Harsent, \& Metzler, 1996).

In the experiments reported here, we have attempted to capture a dissociation reflecting differences between old and young subjects with respect to the maintenance of item and source memory (see, e.g., Johnson, Hashtroudi, \& Lindsay, 1993). The notion that source memory is selectively impaired in the elderly has been advanced by a number of authors in the aging domain and is supported by patterns evident within both single (e.g., Park \& Puglisi, 1985) and multiple tasks (e.g., Perlmutter, Metzger, Nezworski, \& Miller, 1981), as well as in meta-analytic results (Spencer \& Raz, 1995). The results reported here extend this idea by empirically dissociating the contributions of item and source memory.

Furthermore, we show how a similar pattern obtains in a single sample of young adults when the time pressure of the memorial decision is manipulated. When a very quick judgment is required, the source information normally used by young subjects is not available, and the patterns of responding look remarkably similar to those shown by the older subjects. Empirical parallels between aging and response speeding, as well as other resourceconsuming variables, such as divided attention, have been noted by other authors (e.g., Rabinowitz, Craik, \& Ackerman, 1982), although we do not emphasize them here.

We used a procedure similar to the one employed by Jacoby and his colleagues (e.g., Jacoby, 1991, 1999; Jennings \& Jacoby, 1997) that is a variant of the standard recognition paradigm. For example, Jacoby (1999) had old and young subjects attempt to discriminate between previously heard and previously read words by accepting the former and rejecting the latter in a memory test. He found that, as the number of repetitions of a read word increased, young subjects were more able to correctly reject those words. However, for the older subjects, repetition increased the likelihood of incorrectly saying "yes" to previously read words. Jacoby's conclusion-consistent with the results discussed earlier-is that older subjects suffer particularly with recollection, or the ability to actually remember details of the study episode. On the other hand, familiarity, or the generic sense of pastness due to the prior study, appeared to be entirely intact in the older subjects. Similar paradoxical effects of repetition have been found by Bartlett, Strater, and Fulton (1991) in a false-fame paradigm and in an experiment by Schacter, Koutstaal, Johnson, Gross, and Angell (1997), in which multiple exposures to a photograph increased older, but not younger, subjects' false belief that the event was shown on a separate videotape.

In the experiments reported here, item and source memory were examined both when they acted in concert and when they were put in opposition to one another. Following the logic, if not the letter, of Jacoby's opposition procedure, the individual processes of item and source memory are inferred from the manner in which perfor- mance between the two tasks differs. In the typical source memory experiment, in which the differential effects of variables on item and source memory are assessed, poorly defined measurement scales make it difficult to determine when performance on one memory test has been affected more than performance on the other. One advantage of the procedure used here is that it minimizes the reliance on such single dissociative logic (see Dunn \& Kirsner, 1988).

We additionally make use of the robust and reliable beneficial effects of spacing study presentations on memory (e.g., Glenberg, 1976). The spacing effect reveals itself, under most testing conditions, as the result that multiple study opportunities are more beneficial when those opportunities are spaced apart in time than when they are presented very close in time. Because Balota, Duchek, and Paullin (1989) have shown that young and elderly subjects exhibit qualitatively similar spacing effects, it is a particularly appropriate manipulation for the experiments presented here. It is clear from previous work that spaced presentations enhance item memory (relative to massed presentations), but the effects of spacing on memory for context or source is less clear. Given the agerelated decline in the ability to use source information, we hypothesized that spacing might enhance source memory more in the young than in the old subjects.

If this hypothesis is correct, it follows that, on a standard test of recognition, spacing at the time of study should enhance performance in both groups. Because performance in recognition is substantially more dependent on item memory than on source memory-subjects need only discriminate between experimental and extra-experimental sources-both young and older adults should be able to use intact item information as an accurate basis for the decision. However, in a situation where two different lists are presented at study and subjects are asked to endorse items from one of those lists and reject items from the other, spacing should have a more complex effect. For young people, spacing is assumed to boost both item and source memory, so for them spacing will affect performance in two ways. For to-be-endorsed items, it will simply increase the probability of a positive response, because either item or source memory, or both, for the item in question are compatible with a "yes" response. However, for to-be-rejected items, source and item memory are set in opposition: Although the item information will make spaced items more familiar than massed ones, source information will allow younger subjects to localize the source of that familiarity to the to-be-rejected list and thus counter the effects of item memory. Thus, to-berejected items should show an attenuated spacing effect. Depending on the relative contributions of item and source memory to the recognition decision at the time under those conditions, the spacing effects might even disappear or reverse.

For older subjects, spacing in the to-be-rejected list will increase item memory but-if the use of source information is impaired in this group — not provide for opposition by source memory. Thus, such spaced items are 
more likely to be wrongly accepted as being from the other list than are massed items. This proposition was tested in Experiment 2. (For more detail on the logic of opposition testing, see Jacoby, 1991, 1999.)

In Experiment 1, we explored the possibility of obtaining a similar dissociation on a within-subjects basis in young adults. Results have shown (e.g., Hintzman \& Curran, 1994) that information regarding the general familiarity of a stimulus is available more immediately than is information regarding the source of that familiarity, such as the context in which the stimulus was encountered. Other authors have capitalized on that result and demonstrated interactions in recognition performance between speeded and unspeeded testing as a function of repetition (Jacoby, 1999), repetition of semantically related words (Benjamin, in press), and elaborative versus maintenance rehearsal (Benjamin \& Bjork, 2000).

By imposing time pressure on the exclusion decision, it was thought that the contribution of source information to this judgment could be minimized. If so, exclusion performance by young subjects under speeded conditions should resemble the predicted pattern for older adults: False alarms should increase with spacing for tobe-rejected items.

\section{EXPERIMENT 1}

In Experiment 1, we attempted to dissociate the effects of source memory on exclusion judgments in a within-subjects manner. In this experiment, by limiting response time, we hoped to shift the balance of the bases for the memory decisions to one more influenced by item memory or familiarity.

On the test, the subjects were required to endorse only those items from one previously studied list or the other. On this test of "exclusion," unlike on a standard recognition test, merely remembering that an item has been presented is not sufficient to motivate an endorsement of that item; only recall of which particular list that item was shown in can lead to a correct "yes" response. Thus, if spacing affects memory for context as well as content, it should operate to foster performance in two distinct ways: Spaced words in the to-be-endorsed list will be correctly identified as from that list more often than massed words and thus be endorsed more frequently. However, spaced words in the to-be-rejected list will also be sourced correctly more often, and thus will motivate rejection more often than the massed items from that list.

Under speeded conditions, however, in which the availability of source information to the memorial decision might be compromised, positive responding will increase with spacing irrespective of the study-list status of the item. That is, because item information cannot be counteracted with source information under such pressured conditions, false alarms to to-be-rejected items should increase with spacing.

This general paradigm has been referred to as the opposition procedure by Jacoby (e.g., 1999) to emphasize that, in the latter case, the relationship between one memorial basis (item memory) and the evidence in support of a "yes" response is positive as a function of the manipulation (in our case, spacing), and the relationship between the other memorial basis (source memory) and the evidence in favor of a "yes" response is negative. If source memory is absent or impaired and item memory is the principal basis on which decisions can be made, the evidence supporting a positive response increases with spacing, independent of which list that item had been presented in.

\section{Method}

Subjects. Thirty-five students (mean age $=21$ years) from the University of Toronto participated for course credit. Mean performance on the Mill Hill vocabulary test was $52 \%$.

Design. The experiment employed a 2 (test speed) $\times 2$ (study list) $\times 2$ (repetition condition) factorial within-subjects design. In addition, new (unstudied) items were included on both tests as distractors and are analyzed separately.

Materials. The entire experiment was conducted on a PC desktop computer programmed in QuickBasic. The words used were all medium-frequency nouns.

Procedure. During the study phase, the subjects studied two lists of words with a 4-min arithmetic distraction interval between the two. Each list contained 40 words, each of which was presented twice. Half of those items were presented in a massed fashion (only one intervening item), and half were presented in a spaced fashion (five intervening items). Each list was presented in a distinctive color (either blue or red), which was counterbalanced across subjects. The subjects were informed that their task was to attempt to remember as many of the words from both lists as possible and that the words would be presented twice in order to help them. Each item was presented for $1.5 \mathrm{sec}$, and there was a .5 -sec interval between presentations.

After the study phase and a short break (ca. 1 min) during which the subjects responded to short autobiographical questions, the subjects were instructed about the nature of the exclusion test. Half of the subjects were told to respond "yes" only to items from the first list, and half were told to respond positively only to items from the second list. It was emphasized that they should respond "no" both to new items and to the items from the other list.

The test was composed of 80 new and 80 old words, of which half were from the first studied list and half from the second. Each half of the test contained an equal number of old and new items (40), as well as an equal number of massed and spaced old items (20). The first half of the test was conducted in an unspeeded manner: The subjects were allowed as much time as they needed to make a decision. On the second half of the test, the subjects were required to make a decision within a 750-msec deadline. If they did not, their responses were timed out, and they were warned to make their decisions more quickly. The unspeeded test was always administered first in order to acclimate the subjects to the exclusion procedure. Placing the speeded test second typically reduces the frequency of postdeadline responses, especially for the first few items on the test.

At the conclusion of the experiment, the subjects were debriefed and thanked for their participation.

\section{Results}

All inferential statistics reported in this section and throughout this article are reliable at the $p<.05$ on twotailed tests unless otherwise noted. The mean proportions of "yes" responses are shown in Figure 1. Because target list order did not interact with any other variables, the results presented here are collapsed across whether subjects were asked to endorse List 1 or List 2 . An average 

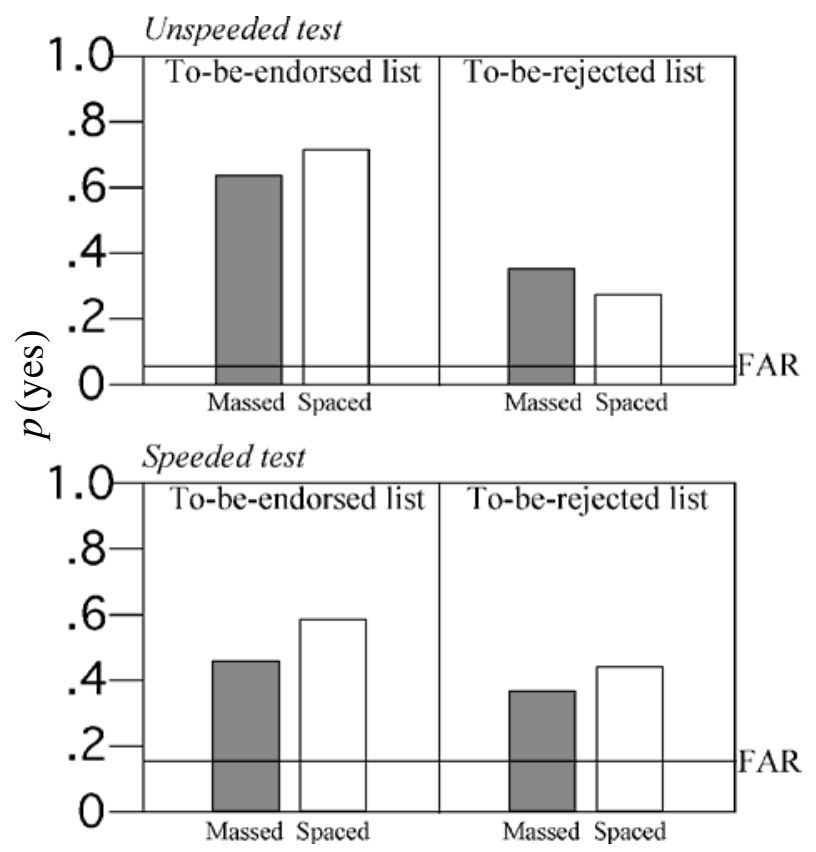

Figure 1. Exclusion performance for young subjects under normal (top) and speeded (bottom) testing conditions. FAR = false-alarm rate for new items.

of 7.4 responses per subject were timed out in the speeded test condition and are not included in the analysis.

On the unspeeded exclusion test, an interaction between repetition condition and study list is evident: The rate of positive responses increased with spacing for the to-beendorsed list but not for the to-be-rejected list $[F(1,34)=$ 4.14]. Positive responses increased with spacing for tobe-endorsed items $[t(34)=2.04]$ but decreased with spacing for to-be-rejected items $[t(34)=2.42]$.

On the speeded test, no such interaction is apparent. Positive response rates increased both for to-be-endorsed $[t(1,34)=2.93]$ and to-be-rejected items $[t(1,34]=1.75$, $p<.05$, one-tailed]. Although the three-way interaction between test type, repetition condition, and item type was not reliable, the critical simple two-way interaction between spacing condition and test type for to-be-rejected items was $F(1,34)=4.19$.

The overall rates of positive responses increased for to-be-rejected items under speeded conditions $[t(1,34)=$ 2.64], and, as might be expected, false alarm rates to truly new items increased on the speeded test of exclusion $[t(34)=3.54]$.

\section{Discussion}

In Experiment 1, we revealed a dissociation between item and source memory in a completely within-subjects design using testing speed as a basis for controlling the contribution of source memory to the exclusion decision. Under normal, unpressured conditions, spacing increased young subjects' ability both to endorse to-beendorsed items and to reject to-be-rejected items. Such an ability reflects the contribution of source memory to the exclusion decision. On the speeded test, we can see that, whereas spacing helped subjects endorse items that are to be recognized, it actually hindered their ability to reject items from the other list. Such a result can be explained by the "unchecked" contribution of item memory to the exclusion decision: Because source memory is compromised under such pressured conditions, the enhancing effects of spacing on item memory led subjects to false alarm to spaced items from the contraindicated list more than to massed items. It is interesting to note that the overall rate of positive responses for to-be-rejected items is greater on the speeded test, as one might expect under conditions in which the contribution of source memory has been limited. In part, this increase with speeding owes to the lower criterion ${ }^{1}$ set in the speeded $\left(C_{j}=.30\right)$ than the unspeeded $\left(C_{j}=.54\right)$ condition $[t(34)=2.30]$.

If it is true that source memory is selectively compromised in the elderly, a dissociation similar to the one evident as a function of time pressure should obtain between young and old subjects. In Experiment 2, we addressed this prediction.

\section{EXPERIMENT 2}

In Experiment 2, subjects again studied two lists of words, in both of which each to-be-learned word was presented twice, in either a massed or spaced fashion. They then engaged in the two memory tests, the first of which was a standard recognition test for all of the previously studied words. The purpose of this test was to ensure that the spacing manipulation had a similar effect on item memory in young and old adults. The second task was an exclusion test of the sort employed in Experiment 1, but with no time pressure manipulation.

The prediction for young subjects was that, as in Experiment 1 , the probability of endorsing an item as having been from a specified target list should increase with spacing if the item is indeed from that list; if the item is from the to-be-rejected list, the proportion of "yes" responses should not increase, since spacing will have had the dual effect of enhancing source and item memory in these subjects.

For older subjects, who presumably lack the memorial basis on which to reject items from the contraindicated list, false alarms should increase with spacing for those to-be-rejected items. The critical prediction is of the three-way interaction between age, study list, and repetition condition on the results from the exclusion test. Specifically, the proportion of "yes" responses to items from the to-be-rejected list should increase with spacing for the older but not the younger group.

\section{Method}

Subjects. Eighteen undergraduates from the University of Toronto participated in order to gain course credit. Fourteen were female and 4 were male. The mean age was 20.7 years, and they had an average of 15.4 years of education. Mean performance on the 
Mill Hill vocabulary test was 53\%. Thirty-four elderly subjects (25 female and 9 male) were recruited from the Toronto area to participate in the experiment. Mean age was 72.7 years, with an average of 15.7 years of education. Mean performance on the Mill Hill vocabulary test was $75 \%$.

Design. We employed a 2 (age group) $\times 2$ (test type) $\times 2$ (study list) $\times 2$ (repetition condition) mixed design. All variables were manipulated within subjects except for age group. In addition, new (unstudied) items were included on both tests as distractors and are analyzed separately.

Materials. As in the previous experiment, the entire routine was implemented on a PC-compatible microcomputer programmed in QuickBasic. The study and test items were the same as in the previous experiments.

Procedure. The study phase of the experiment was equivalent to that used in Experiment 1. Following a short distractor interval, all subjects engaged in the recognition test. They were instructed to respond "yes" to any previously seen words and "no" to words that they believed to be new. The recognition test contained 80 words, 40 of which had been studied previously and 40 of which were new. Of the 40 old items, 20 had been presented in a massed fashion and 20 in a spaced fashion. An equal number of items (10 from each repetition condition) from study lists 1 and 2 were used. Furthermore, each half of the recognition test contained an equal number of old and new items (20) and an equal number of massed and spaced items (10).

The 80 -item exclusion test was made up in the same manner as the recognition test. No items appeared in both the recognition and the exclusion tests. Unlike in the previous experiment, no time pressure was administered during the task. After concluding the test of exclusion, all subjects were debriefed and thanked for their participation.

The only procedural difference between the young and old subjects occurred during the distractor interval. Because the biographical questions presented during the distraction interval were oriented around university life for the young subjects, these questions were altered to make them appropriate for the subjects not currently enrolled in university.

\section{Results}

Figure 2 presents the recognition results from Experiment 2 . As can be seen, the spacing effect obtained on the test of recognition for both the young $[t(17)=3.12]$ and old $[t(33]=2.03]$ subjects. The false-alarm rate was higher for the older subjects $[t(50)=2.49]$, as has been reported elsewhere (Schacter et al., 1997).

Figure 3 shows the results from the exclusion test. For young subjects, items from the to-be-endorsed list showed a comparable spacing effect to that evidenced on the test

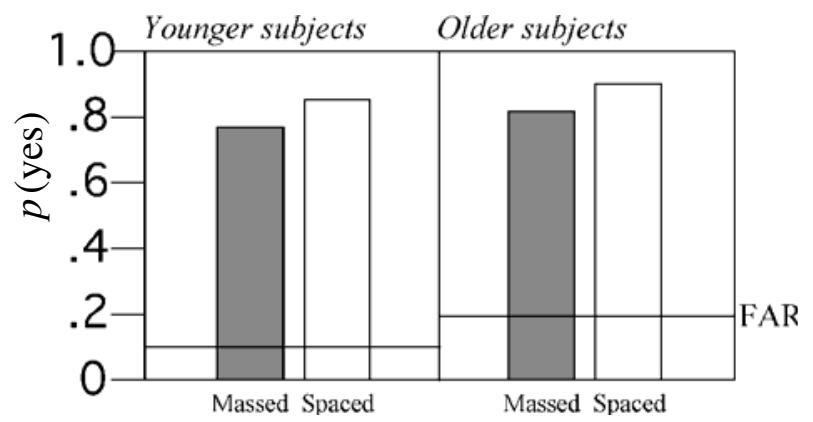

Figure 2. Recognition performance for young (left) and old (right) subjects. FAR = false-alarm rate for new items.

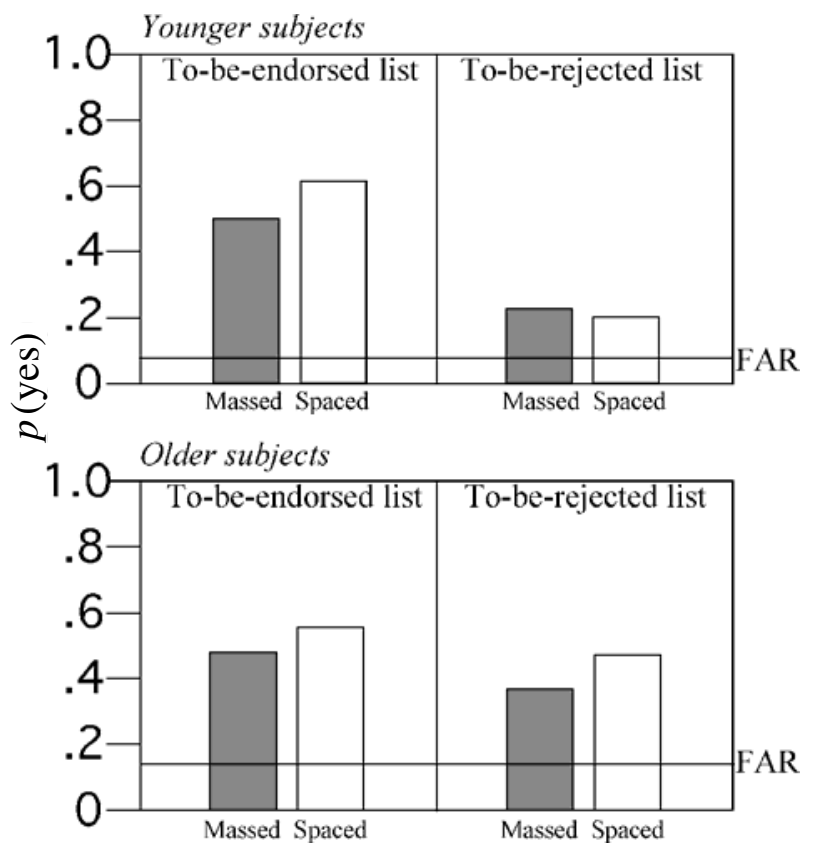

Figure 3. Exclusion test performance for young (top) and old (bottom) subjects. FAR = false-alarm rate for new items.

of recognition $[t(17)=2.52]$. However, items from the to-be-rejected list show no such pattern. The simple interaction between repetition condition and study list was reliable $[F(1,17)=5.26]$.

For older subjects, the effects of spacing on the items drawn from the to-be-endorsed list was small but reliable $[t(33)=1.75, p<.05$, one-tailed $]$. More critically, the difference involving items from the to-be-rejected list obtained: False alarms were committed more frequently for spaced than for massed items $[t(33)=2.11]$.

Most importantly, the three-way interaction between age, list, and repetition was reliable $[F(1,50)=3.18]$.

\section{Discussion}

As predicted, the pattern of results on the exclusion test as a function of spacing differed for young subjects depending on whether the list was to be rejected or endorsed. For words that were from the to-be-accepted list, increases in both item and source memory fostered positive responding. For words from the other list, item and source memory were in opposition: Intact source memory led the subjects to reject the item, despite the enhancement of item memory resulting from the spacing manipulation. It is for this reason that the spacing effect apparent for items on the to-be-endorsed list did not obtain for items from the other list. Because source information "trumps" item information, it is sufficient to counteract the effect of spacing on item memory. Unlike in Experiment 1, the spacing effect in young subjects did not reverse for to-be-rejected items, but it did disappear. As argued earlier, the critical prediction is of an interaction between spacing and list type, which did obtain. 
Procedural differences between the two experimentsincluding the recognition test administered in Experiment 2 but not Experiment 1-likely contributed to this minor difference in results.

Also as predicted, the effect of spacing on to-be-rejected items increased the probability of incorrect endorsements of those items for the older subjects. Such an effect did not arise in the young subjects, presumably because they had a different memorial basis on which to make the decision-namely, an increase in source memory with which to counteract the increase in item memory.

\section{GENERAL DISCUSSION}

The present experiments were conducted to demonstrate the dissociability of item and source information in recognition memory, to examine the effects of time pressure at retrieval on young adults' ability to use these two types of information, and to assess the complex effects of spacing on exclusion. To accomplish these goals, words were presented for initial encoding under massed or spaced conditions; it was known that spacing would increase recognition performance overall, but we wished to explore whether the manipulation had its effect on memory for content, memory for context, or both.

The results of the standard recognition test used in Experiment 2 showed that spacing increased recognition performance by about $10 \%$ in both younger and older subjects (Figure 2). We might speculate that this increase was a result of enhanced item information. For the younger adults, however, spacing also appeared to enhance source memory, given that they were more likely to correctly reject spaced words than massed words from the to-berejected list in Experiment 2 and under the unspeeded conditions in Experiment 1. Our account of this result (following Jacoby, 1991, 1999) is that item and source information are in opposition in the exclusion test: The enhanced item information makes words from the to-berejected list more familiar and thus more likely to be incorrectly endorsed, but the enhanced source information counteracts this tendency by facilitating attribution of the increased familiarity to presentation on the to-berejected list. Thus, for the young adults, spacing led to more items being judged correctly as "old," and also to a greater proportion of these items being correctly assigned to their presentation list. When young adults were tested under speeded conditions, however, spacing was associated with an increase in falsely endorsed items from the to-be-rejected list. Given that the encoding conditions were identical for words tested under speeded and unspeeded conditions, we assume that spacing enhanced item and source information in all cases but that the speeded test condition prevented the subjects from utilizing the enhanced source information. The enhancement in item information was thus unopposed and resulted in an increase in falsely endorsed items.

The older adults in Experiment 2 showed the same pattern of results as the young adults working under speeded test conditions; that is, spacing was associated with an increase in falsely endorsed words from the tobe-rejected list. We know from the results of the recognition test in Experiment 2 that spacing enhanced item information in the older adults and thus conclude that source information was lacking in that group. In the case of the young subjects in the speeded conditions, we conclude that they had encoded the extra source information but were unable to utilize it. It is possible that the analogous result for the older group is also attributable to a failure of utilization, but it is more likely that spacing failed to enhance source information at the time of encoding in the older adults.

It should be noted that we are not attempting to claim that speeding response "mimics" the effects of age in any meaningful way. In particular, it is quite possible that source encoding is partially responsible for the inability of older subjects to use source information to the degree utilized by younger subjects. For young subjects tested under speeded conditions, only source utilization is compromised. The similar pattern of results between the two cases likely reflects more about a general gradient of task difficulty than about any particularly meaningful analogy between aging and speeding response.

The results of Experiment 2 are consistent with the observation discussed in the introduction of this article: Older subjects suffer disproportionate impairment in their memory for source, as opposed to item information. Older subjects are more likely to commit false alarms to recently studied distractors that were learned well than to those that were not learned as well. Young subjects under normal testing conditions were more able to reject such distractors when they had been learned well, suggesting that they had an additional basis for the decision that was unavailable to the old. However, under conditions of time pressure during the decision, the performance of young subjects mirrored that of old subjects: False alarms to contraindicated list members increased with spacing. This result and the qualitative "reversion" to the pattern evident in older adults suggests that source memory is a process affected not only by age, but also by general conditions of stress or pressure. It is interesting to note that, when older subjects are encouraged to adopt more stringent recognition decision criteria-in essence, the opposite of what speeding response appears to do-source memory differences between young and old on a falsefame task are attenuated (Multhaup, 1995).

We have argued here that source memory is compromised in the elderly and in the young under conditions of time pressure. At an anecdotal level, it appears as though instances in which we fail to coordinate item and source information increase under general conditions of stressthat is, we might be more likely, for example, to confuse our children's names when flustered by their actions or even, under conditions of even greater exasperation, to call them by our dog's name. Moreover, the results from numerous experiments suggests disproportionate impairment in memory for source in older adults (Spencer \& Raz, 1995). Using the opposition procedure, we have revealed a dissociation between age group and memory for 
source and have shown how an analogous dissociation can be obtained in a single sample of younger adults by imposing time pressure at test. It is our hope that these two contributions further our understanding of source memory and the parallel but not necessarily equivalent effects that aging and time pressure exhibit on the contribution of source information to memorial decisions.

\section{REFERENCES}

Balota, D. A., Duchek, J. M., \& Paullin, R. (1989). Age-related differences in the impact of spacing, lag, and retention interval. Psychology \& Aging, 4, 3-9.

Bartlett, J. C., Strater, L., \& Fulton, A. (1991). False recency and false fame of faces in young adulthood and old age. Memory \& Cognition, 19, 177-188.

Benjamin, A. S. (in press). On the dual effects of repetition on false recognition. Journal of Experimental Psychology: Learning, Memory, \& Cognition.

Benjamin, A. S., \& BJork, R. A. (2000). Dissociating recognition speed and accuracy for words rehearsed via primary versus secondary rehearsal. Journal of Experimental Psychology: Learning, Memory, \& Cognition, 26, 638-648.

Benjamin, A. S., Kester, J. D., Craik, F. I. M., \& Black, S. (in press). Pathological familiarity and false recognition: A case study. Brain \& Cognition.

Craik, F. I. M., \& JACOBY, L. L. (1996). Aging and memory: Implications for skilled performance. In W. A. Rogers, A. D. Fisk, \& N. Walker (Eds.), Aging and skilled performance: Advances in theory and applications (pp. 113-137). Mahwah, NJ: Erlbaum.

Craik, F. I. M., \& Jennings, J. M. (1992). Human memory. In F. I. M. Craik \& T. A. Salthouse (Eds.), The handbookof aging and cognition (pp. 191-211). New York: Plenum.

Curran, T., Schacter, D. L., Norman, K. A., \& Galluccio, L. (1997). False recognition after a right frontal lobe infarction: Memory for general and specific information. Neuropsychologia, 35, 1035-1049.

Dunn, J. C., \& KirSner, K. (1988). Discovering functionally independent mental processes: The principle of reversed association. Psychological Review, 95, 91-101.

Glenberg, A. M. (1976). Monotonic and nonmonotonic lag effects in paired-associate and recognition memory paradigms. Journal of Verbal Learning \& Verbal Behavior, 15, 1-16.

Hashtroudi, S., Johnson, M. K., \& Chrosniak, L. D. (1989). Aging and source monitoring. Psychology \& Aging, 4, 106-112.

Hintzman, D. L., \& CurRan, T. (1994). Retrieval dynamics of recognition and frequency judgments: Evidence for separate processes of familiarity and recall. Journal of Memory \& Language, 33, 1-18.

JACOBY, L. L. (1991). A process-dissociation framework: Separating automatic from intentional uses of memory. Journal of Memory \& Language, 30, 513-541.

JACOBY, L. L. (1999). Ironic effects of repetition: Measuring age-related differences in memory. Journal of Experimental Psychology: Learning, Memory, \& Cognition, 25, 3-22.
JENNINGS, J. M., \& JACOBY, L. L. (1997). An opposition procedure for detecting age-related deficits in recollection: Telling effects of repetition. Psychology \& Aging, 12, 352-361.

Johnson, M. K., Hashtroudi, S., \& Lindsay, D. S. (1993). Source monitoring. Psychological Bulletin, 114, 3-28.

Kausler, D. H., \& Puckett, J. M. (1981). Adult age differences in memory for sex of voice. Journal of Gerontology, 36, 44-50.

Kimberg, D. Y., \& FARAH, M. J. (1993). A unified account of cognitive impairments following frontal lobe damage: The role of working memory in complex, organized behavior. Journal of Experimental Psychology: General, 122, 411-428.

MANDLER, G. (1980). Recognizing: The judgment of previous occurrence. Psychological Review, 87, 252-271.

McIntyre, J. S., \& Craik, F. I. M. (1987). Age differences in memory for item and source information. Canadian Journal of Psychology, 41, 175-192.

Multhaup, K. S. (1995). Aging, source, and decision criteria: When false-fame errors do and do not occur. Psychology \& Aging, 10, 492-497.

PARK, D. C., \& Puglisi, J. T. (1985). Older adults' memory for the color of pictures and words. Journal of Gerontology, 40, 198-204.

Parkin, A. J., Bindschaedler, C., Harsent, L., \& Metzler, C. (1996). Pathological false-alarm rates following damage to the left frontal cortex. Brain \& Cognition, 32, 14-27.

Perlmutter, M., Metzger, R, Nezworski, T., \& Miller, K. (1981). Spatial and temporal memory in 20 to 60 year olds. Journal of Gerontology, 36, 59-65.

Rabinowitz, J. C., Craik, F. I. M., \& Ackerman, B. P. (1982). A processing resource account of age differences in recall. Canadian Journal of Psychology, 36, 325-344.

Schacter, D. L., Koutstaal, W., Johnson, M. K., Gross, M. S., \& ANGELL, K. E. (1997). False recollection induced by photographs: A comparison of older and younger adults. Psychology \& Aging, 12, 203-215.

Schacter, D. L., Osowiecki, D., Kaszniak, A. W., Kihlstrom, J. F. \& VALDESSERI, M. (1994). Source memory: Extending the boundaries of age-related deficits. Psychology \& Aging, 9, 81-89.

SPENCER, W. D., \& RAz, N. (1995). Differential effects of aging on memory for content and context: A meta-analysis. Psychology \& Aging, 10, 527-539.

Tulving, E. (1983). Elements of episodic memory. New York: Oxford University Press.

Verhaeghen, P., Marcoen, A., \& Goossens, L. (1993). Facts and fiction about memory aging: A quantitative integration of research findings. Journals of Gerontology: Psychological Sciences, 48, P157-P171.

\section{NOTE}

1. The measure used here, $C_{j}$, is defined as the inverse normal transform of the false-alarm rate.

(Manuscript received August 2, 1999; revision accepted for publication March 26, 2001.) 